\title{
PIIISGUC.ORG
}

"iş, GÜÇ" ENDÜSTRi iLişKILERI VE INSAN KAYNAKLARI DERGISi

"IS, GUC" INDUSTRIAL RELATIONS AND HUMAN RESOURCES JOURNAL

\section{İş Güvencesizliği Algısının Çalışanların Kaygı Düzeyleri Üzerine Etkisi: Bir Uygulama}

\author{
Yard.Doç.Dr.Salih DURSUN \\ Karadeniz Teknik Üniversitesi, İktisadi ve İdari Bilimler Fakültesi, \\ Çalışma Ekonomisi ve Endüstri İlişkileri Bölümü
}

\section{Prof.Dr.Nuran BAYRAM}

Uludağ Üniversitesi, İktisadi ve İdari Bilimler Fakültesi, Ekonometri Bölümü

Temmuz/July 2013, Cilt/Vol: 15, Say1/Num: 3, Page: 20-27

ISSN: 1303-2860, DOI: 10.4026/1303-2860.2013.0229.x

Makalenin on-line kopyasına erişmek için / To reach the on-line copy of article:

http://www.isguc.org/index.php?p=article\&id=507\&cilt=15\&sayi=2\&yil=2013

Makale İçin İletişim/Correspondence to:

Yard.Doç.Dr.Salih Dursun/ Email: ercandursun28@gmail.com 


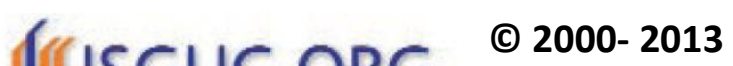 \\ "İş,Güç" Endüstri ilişkileri ve İnsan Kaynakları Dergisi "Işs,Güç" Industrial Relations and Human Resources Journal
}

\author{
Temmuz/July 2013, Cilt/Vol: 15, Say1/Num: 3, \\ Sayfa/Page: 20-27, DOI: 10.4026/1303-2860.2013.0229.x
}

"İş,Güç" Endüstri İlişkileri ve İnsan Kaynakları Dergisi, yılda dört kez yayınlanan hakemli, bilimsel elektronik dergidir. Çalışma hayatına ilişkin makalelere yer verilen derginin temel amact; belirlenen alanda akademik gelişime ve paylaşıma katkıda bulunmaktır.

"İş,Güç" Endüstri İlişkileri ve İnsan Kaynakları Dergisi'nde, 'Türkçe' ve 'İngilizce' olarak iki dilde makale yayınlanmaktadır. "İş,Güç" Endüstri İlişkileri ve İnsan Kaynakları Dergisi, ulusal ve uluslararası birçok indekste taranmaktadır. (Cabell's Directories, Ebsco Socindex, Index Islamicus, Index Copernicus International, Worldwide Political Science Abstracts, Sociological Abstract, Ulakbim Sosyal Bilimler Veritabanı, ASOS Index)

Editör / Editor in Chief

Aşkın Keser (Uludağ University)

\section{Editör Yardımcıları / Co-Editors}

Şenol Baştürk (Uludăg University)

K.Ahmet Sevimli (Uludağ University)

Gözde Yllmaz (Marmara University)

\section{Uygulama / Design}

Yusuf Budak (Kocaeli University)

Tarandiğı Indeksler / Indexes ASOS INDEX

CABELL'S DIRECTORIES EBSCO SOCINDEX

Index ISLAMICUS

Index COPERNICUS Int.

Sociological Abstract

ULAKBİM Sosyal Bilimler

Veritanı

Worldwide Political Science

Abstracts

\author{
Yayın Kurulu / Editorial Board \\ Dr.Şenol Baştürk (Uludă̆ University) \\ Yrd.Doç.Dr.Zerrin Fırat (Uludă̆ University) \\ Doç.Dr.Aşkın Keser (Uludă̆ University) \\ Prof.Dr.Ahmet Selamoğlu (Kocaeli University) \\ Yrd.Doç.Dr.Ahmet Sevimli (Uludağ University) \\ Doç.Dr.Abdulkadir Şenkal (Kocaeli University) \\ Doç.Dr.Gözde Yılmaz (Marmara University) \\ Yrd.Doç.Dr.Memet Zencirkıran (Uludă̆ University)
}

Uluslararası Danışma Kurulu / International Advisory Board

Prof.Dr.Ronald Burke (York University - Kanada)

Assoc.Prof.Dr.Glenn Dawes (James Cook University - Avustralya)

Prof.Dr.Jan Dul (Erasmus University - Hollanda)

Prof.Dr.Alev Efendioğlu (University of San Francisco - ABD)

Prof.Dr.Adrian Furnham (University College London - Ingiltere)

Prof.Dr.Alan Geare (University of Otago - Yeni Zellanda)

Assoc. Prof. Dr. Diana Lipinskiene (Kaunos University - Litvanya)

Prof.Dr.George Manning (Northern Kentucky University - ABD)

Prof.Dr.Mustafa Özbilgin (Brunel University - UK)

Assoc. Prof. Owen Stanley (James Cook University - Avustralya)

Prof.Dr.Işık Urla Zeytinoğlu (McMaster University - Kanada)

Ulusal Danışma Kurulu / National Advisory Board

Prof.Dr.Yusuf Alper (Uludă̆ University)

Prof.Dr.Veysel Bozkurt (Ístanbul University)

Prof.Dr.Toker Dereli (Işık University)

Prof.Dr.Nihat Erdoğmuş (İstanbul Şehir University)

Prof.Dr.Ahmet Makal (Ankara University)

Prof.Dr.Süleyman Özdemir (İstanbul University)

Prof.Dr.Ahmet Selamoğlu (Kocaeli University)

Prof.Dr.Nadir Suğur (Anadolu University)

Prof.Dr.Nursel Telman (Maltepe University)

Prof.Dr.Cavide Uyargil (İstanbul University)

Prof.Dr.Engin Yildırım (Anayasa Mahkemesi)

Doç.Dr.Arzu Wasti (Sabancı University)

Dergide yayınlanan yazllardaki görüşler ve bu konudaki sorumluluk yazarlarına aittir.

Yayınlanan eserlerde yer alan tüm içerik kaynak gösterilmeden kullanılamaz.

All the opinions written in articles are under responsibilities of the authors.

The published contents in the articles cannot be used without being cited. 


\title{
İş Güvencesizliği Algısının Çalışanların Kaygı Düzeyleri Üzerine Etkisi: Bir Uygulama
}

\author{
Yard.Doç.Dr.Salih DURSUN \\ Karadeniz Teknik Üniversitesi, İktisadi ve İdari Bilimler Fakültesi, \\ Çalışma Ekonomisi ve Endüstri İlişkileri Bölümü
}

Prof.Dr.Nuran BAYRAM

Uludağ Üniversitesi, İktisadi ve İdari Bilimler Fakültesi, Ekonometri Bölümü

\section{Effect Of Job Insecurity Perception On Employees'}

\author{
Anxiety Levels: A Case Study
}

\begin{abstract}
The increasing trends indownsizing, corporate restructuring, and part-time labor in both public and private sectors have made job insecurity an important development on employees' both physical and emotional wellbeing. This paper thus seeks to explain the effect of job insecurity perception on employees' anxiety levels. The 147 participants were sampled from two companies in the private sector. Of those, 27.9 percent are women, with 72.1 percent men. The average age is $32.92 \pm 8.69$, while the average work experience is 8.14 7 7.39. The data analysis includes descriptive statistics, $t$-test, $F$-test and a regression analysis. The results of the analysis confirm that when job insecurity increases, employees' anxiety levels also worsen. .
\end{abstract}

Key Words: Insecurity perception, anxiety, unemployment.

Özet

Günümüzde gerek kamu, gerekse özel sektörde giderek artan şekilde görülen küçülme, yeniden yapılanma ve esnek çalışma düzenlemeleri iş güvencesizliğini üzerinde önemle durulması gereken konulardan biri haline getirmiştir. Diğer taraftan, iş güvencesizliği çallşanların fiziksel ve ruhsal sağlıkları üzerinde önemli etkilerde bulunmaktadır. Bu çalışmanın amacı, iş güvencesizliği algısının, çalışanların kaygl düzeyleri üzerine etkisini araştırmaktır. Çalışmanın örneklemini, özel sektöre ait iki firmada çalışan 147 kişi oluşturmaktadır. Araştırmaya katılanların yaklaşık \%27,9'u kadın, \%72,1'i

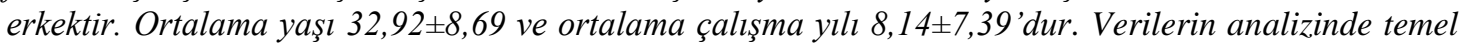
betimsel istatistik analizleri, $t$-testi, $F$ testi ve regresyon analizleri kullanılmıştır. Araştırma bulguları incelendiğinde, algılanan iş güvencesi azaldı̆̆ında çalışanların kaygı düzeylerinin arttı̆̆ sonucu elde edilmiştir.

Anahtar Kelimeler: İş güvencesizliği algısl, kaygl, işsizlik. 


\section{GİRIŞ}

İş güvencesi günümüz çalışma hayatının önemli konularından birini oluşturmaktadır. Günümüzde, dünya genelinde görülen ekonomik ve toplumsal yaşamdaki önemli değişimler, işsizlik oranları, örgütlerde görülen küçülme ve yeniden yapılanmalar, çalışma hayatında esneklik uygulamaları, hızlı değişim vb. faktörler çalışanlarda iş güvencesi anlamında önemli bir kaygı kaynağı olmaktadır. Diğer taraftan, sıklıkla yaşanan ekonomik krizler ve bu krizlerin çalışanlar üzerine yansımaları ve uluslar arası rekabet bu kaygiyı daha da arttırmaktadır.

İş güvencesizliği ile ilgili ilk çalışmalar, 1980'li yıllardan sonra başlamıştır. $\mathrm{Bu}$ dönemden itibaren, başta Avrupa ülkeleri ve ABD olmak üzere birçok ülkede yaşanan, firma kapanmaları, firmaların yeniden yapılanmaları ve geçici iş sözleşmelerindeki artış vb. ekonomik sistemlerdeki değişimler bu gelişmede önemli bir rol oynamıştır (Witte, 2005:1).

Algılanan iş güvencesizliği veya iş güvencesizliği algısı literatürde farklı şekillerde tanımlanmaktadır. Bir tanıma göre, algılanan iş güvencesizliği, çalışanların işlerinin devamlılığ konusunda tehdit algılamaları olarak ifade edilebilir (Erlinghagen, 2008: 183). Bir başka tanımda ise iş güvencesizliği, "bir kişinin, işinin geleceği hakkında duymuş olduğu kaygi" olarak tanımlanmıştır (Hartley ve diğ., 1991: 39). Witte (2005:1) iş güvencesizliğini işini kaybetmeye yönelik tehdit algısı ve bu tehditle ilgili endişeler şeklinde ele almıştır.
Witte (2005:2) iş güvencesizliğinin nedenlerinin 3 başlık altında ele alınabileceğini belirtmiştir. Bunlar; bölgesel veya örgütsel seviyedeki değişkenler (ulusal veya bölgesel işsizlik oranları, örgütsel yapıdaki değişimler vb.), bir kişinin çalışmış olduğu örgütteki pozisyonunu belirleyen özellikleri (yaş, hizmet y1l ve mesleki pozisyon vb.) ve negatif duygudurum veya içsel kontrol odağ 1 gibi kişilik özellikleridir.

Algılanan iş güvencesizliği bireyler ve aileleri, örgütler ve bir bütün olarak değerlendirdiğimizde toplum üzerinde önemli etkilerde bulunmaktadır. Özellikle iş güvencesizliğinin yaratmış olduğu belirsizlik ortamı, bireyler açısından önemli bir stres kaynağıdır (Seçer, 2009:330). Bu konuda yapılan çalışmaların ortaya koyduğu üzere, iş güvencesizliği algısı çalışanların stres düzeylerinin artmasına (Önder ve Wasti, 2002; Dığın ve Ünsar, 2009), kayg1 ve depresyon artışına (Boya ve diğ., 2008), fiziksel ve zihinsel sağlık şikâyetlerinde artışa (Burgard, Brand ve House, 2008; Boya ve diğ., 2009), iş tatminlerinin ve örgütsel bağlllıklarının düşmesine, kurumdan ayrılma niyetinin artmasina (Sverke, Hellgren ve Naswall, 2002; Clark, 2005; Poyraz ve Kama, 2008), motivasyonlarının düşmesine (Bakan ve Büyükbeşe, 2004) neden olmaktadır. Diğer taraftan, iş güvencesizliğinin bireyler ve örgütler üzerine olan etkileri kısa ve uzun döneme göre farklılık gösterdiği kabul edilmektedir (Şekil $1)$.

\begin{tabular}{|c|c|c|}
\hline & Bireysel & Örgütsel \\
\hline Kısa Dönem & $\begin{array}{l}\text { İş Tutumlan } \\
\text { İş Tatmini } \\
\text { İşe Bağlılık }\end{array}$ & $\begin{array}{l}\text { Örgütsel Tutumlar } \\
\text { Örgütsel Bağlılık } \\
\text { Güven }\end{array}$ \\
\hline Uzun Dönem & $\begin{array}{l}\text { Sağlık } \\
\text { Fiziksel Sağlık } \\
\text { Zihinsel Sağlık }\end{array}$ & $\begin{array}{l}\text { İşle İlgili Davranışlar } \\
\text { Performans } \\
\text { Kurumdan Ayrılma Niyeti }\end{array}$ \\
\hline
\end{tabular}

Kaynak: Sverke, Hellgren ve Naswall, 2002:244

Şekil 1. İş güvencesizliğinin Kısa ve Uzun Dönem Etkileri 
İş güvencesizliği kısa dönemde iş tatmini, işe bağlllık gibi işle ilgili tutumlar ve örgütsel bağlllık ve güven gibi örgüte yönelik tutumlar üzerinde etkili olmaktadır. Uzun dönemde ise, iş güvencesizliği, bireylerin fiziksel ve zihinsel açıdan sağlıklarının bozulmasına ve örgütsel açıdan performans ve kurumdan ayrılma niyeti gibi işle ilgili davranışlar üzerinde etkide bulunmaktadır (Sverke, Hellgren ve Naswall, 2002:244).

Diğer taraftan iş güvencesizliği yalnızca çalışanlar ve örgütler üzerinde olumsuz etkide bulunmakla kalmamakta, çalışanların aileleri üzerinde de önemli sorunlara neden olabilmektedir. Özellikle aile içinde çocuklar, iş güvencesizliğinin olumsuz sonuçlarından etkilenebilmektedir. $\mathrm{Bu}$ anlamda iş güvencesizliği, çocukların gelecek anlamında kaygı duymalarına, akademik anlamda başarılarının düşmesine, çalışma değerleri ve tutumlarının biçimlendiği sosyalleşme sürecinde önemli etkilere sahip olduğu görülmektedir (Çakır, 2007:135).

$\mathrm{Bu}$ çalışmanın amacı, iş güvencesizliği algısının çalışanların kaygı düzeyleri üzerine etkisinin ortaya konulmasıdır. Çalışmanın bir diğer amacı da, iş güvencesizliği algısının, yaş, cinsiyet, medeni durum, eğitim durumu, işteki konum gibi demografik faktörlere göre farklılıklarının tespit edilmesidir.

\section{YÖNTEM}

\subsection{Veri Toplama Araçları}

İş Güvencesi Endeksi: Çalışanların iş güvencesine ilişkin algılamalarının ölçülmesinde kullanılan ölçek oluşturulurken, Probst (1998) tarafından geliştirilen ve Önder ve Wasti (2002) tarafından Türkiye'de geçerlilik ve güvenilirlik analizleri yapılan "İş Güvencesi Endeksi”nden yararlanılmıştır. Ölçek $3^{\prime}$ ü olumlu ve 3 'ü olumsuz olmak üzere 6 sorudan oluşmaktadır. Katılımclar cevaplarını "evet", "hayır" ve "?" seçeneklerinden birini tercih ederek vermektedirler. İş güvencesi algısı hesaplanırken evet seçeneği 3 puan, hayır seçeneği 0 puan ve "?" seçeneği ise 1 puan üzerinden değerlendirilmektedir. Ölçekten elde edilen toplam veya ortalama puanlar arttıkça iş güvencesi algısı artmaktadır.

Spielberger Sürekli Kaygı Ölçeği: (Trait Anxiety Inventory -STAI). Ölçek, bireylerin sürekli kayg1 düzeylerini belirlemek amacıyla Spielberger ve arkadaşları tarafından 1964 yılında geliştirilmiştir. Ölçeğin, Türkçe güvenirlik ve geçerlik çalışmaları Öner ve Le Compte (1983) tarafından yapılmıştır. Sürekli kaygı ölçeği, 14 yaşından büyük gençler ve yetişkinlerde kaygıyı ölçmektedir. Bir tür kendini değerlendirme ölçeği olan bu ölçek, kısa ifadelerden oluşan 20 maddeyi içermektedir. Ölçeğin içerdiği ters maddelerde puanlar tersine çevrilmek kaydıyla, bütün maddeler 1-4 arası puanlanmakta, artan puan yüksek kaygı düzeyini göstermektedir. Ölçekten elde edilen toplam puan değeri 20 ile 80 arasında değişebilmektedir. Puanın yüksek olması kaygı seviyesinin yüksek olduğunu, düşük puan, kaygı seviyesinin düşük olduğunu işaret etmektedir.

\subsection{Katılımcilar}

Çalışmanın örneklemini, Bursa il merkezinde özel sektörde çalışan toplam 147 kişi oluşturmaktadır. Özel sektörde yer alan iki işyerinde-kapalı zarflar halinde dağıtılan anket formları, gönüllü katılımcıların kendileri tarafından doldurulmuş ve bir hafta sonra geri toplanmıştır. Dağıtılan toplam 200 anketten 160 '1 geri dönmüş, 13 anket ise eksik veri içerdiği için değerlendirme dışında bırakılmıştır (geri dönüş oranı, \%80).

\section{BULGULAR}

Çalışmaya katılanların yaşları 16-60 aralığında değişmekte olup, ortalama yaş $32,92 \pm 8,69$ ve ortalama çalışma yılı $8,14 \pm 7,39$ 'dur. Ayrıca, katılımcıların \%27,9'u kadın ve \%72,1'i erkektir. Katılımcıların eğitim durumları açısından dağılımlarına bakıldığında, \%38,1'i üniversite mezunu, \%36,7'si lise mezunu ve \%25,2'si ilkokul/ilköğretim mezunudur. Diğer taraftan, katılımcıların \%62,6'sı evli, \%36,7'si bekârdır. Kullanılan ölçeklerle ilgili güvenirlik analizi sonuçları ise Tablo 1'de görülmektedir. 
Tablo 1. Güvenilirlik Analizi Sonuçları

\begin{tabular}{cccccc}
\hline Ölçekler & Madde Sayısı & N & Ort. & S.Sapma & C. Alpha \\
\hline İş Güvencesi Ölçeği & 6 & 143 & 9.44 & 6.00 & 0.86 \\
Sürekli Kaygı Ölçeği & 20 & 142 & 39.07 & 8.33 & 0.85 \\
\hline
\end{tabular}

Tablo 1'den görüldüğü üzere, tüm ölçeklerin güvenirlik katsayıları 0.85 ile 0.86 arasında değişmekte olup, tüm katsayılar sosyal bilimlerde kabul edilebilir sınırlardadır.

Tablo 2. t-testi ve F-testi Sonuçları

\begin{tabular}{|c|c|c|}
\hline \multirow{2}{*}{ Değişkenler } & \multicolumn{2}{|c|}{ İş Güvencesi Algısı } \\
\hline & $\mathrm{N}$ & Ort \pm ss \\
\hline \multicolumn{3}{|l|}{ Cinsiyet } \\
\hline Erkek & 103 & $1,58 \pm 1,01$ \\
\hline \multirow{3}{*}{ Kadın } & 40 & $1,55 \pm 0,94$ \\
\hline & & $t=0,121$ \\
\hline & & $p=0.904$ \\
\hline \multicolumn{3}{|l|}{ Medeni Durum } \\
\hline Evli & 90 & $1,58 \pm 1.02$ \\
\hline \multirow[t]{3}{*}{ Bekâr } & 52 & $1,58 \pm 0.96$ \\
\hline & & $t=-, 018$ \\
\hline & & $p=0.985$ \\
\hline \multicolumn{3}{|l|}{ Yaş Grupları } \\
\hline 1.30 yaş altı & 68 & $1,37 \pm 1,11$ \\
\hline $2.31-45$ yaş & 58 & $1,82 \pm 1,02$ \\
\hline \multirow[t]{3}{*}{3.46 yaş üstü } & 15 & $1,44 \pm 0,85$ \\
\hline & & $\mathrm{F}=3,332$ \\
\hline & & $p=0,039 \quad 1<2^{*}$ \\
\hline \multicolumn{3}{|l|}{ Eğitim Durumu } \\
\hline 1.̇̇lkokul/İlköğretim & 37 & $1,41 \pm 1,06$ \\
\hline 2.Lise & 51 & $1,47 \pm 0,99$ \\
\hline \multirow[t]{3}{*}{ 3.Üniversite } & 55 & $1,77 \pm 0,94$ \\
\hline & & $\mathrm{F}=1,815$ \\
\hline & & $p=0,167$ \\
\hline \multicolumn{3}{|l|}{ İşteki Konumu } \\
\hline Sözleşmeli & 27 & $0,91 \pm 0,82$ \\
\hline \multirow[t]{3}{*}{ Daimi (Kalıcı) } & 114 & $1,73 \pm 0,98$ \\
\hline & & $t=-3,967$ \\
\hline & & $\mathrm{p}=0,000$ \\
\hline
\end{tabular}

"Tukey 
Yukarıdaki tablo incelendiğinde cinsiyet, medeni durum ve eğitim durumu değişkenlerine göre iş güvencesi algısında istatistiksel olarak anlamlı bir farklılık bulunmadığı görülmektedir $\quad(p>0.05)$. Yaş grupları açısından incelendiğinde, 31-45 yaş grubunun en yüksek iş güvencesi algısına ve 30 yaş altının da en düşük iş güvencesi algısına sahip olduğu istatistiksel olarak \%5 anlamlılık düzeyinde elde edilmiştir $(p<0,05)$. Çalışanların işteki konumu dikkate alındığında ise, sözleşmeli çalışanların iş güvencesi algısının sürekli çalışanlara göre istatistiksel olarak \%1 anlamlılık düzeyinde daha düşük olduğu bulunmuştur $(p<0,01)$.

Tablo 3. Regresyon Analizi Sonuçları

\begin{tabular}{|c|c|c|}
\hline \multirow{2}{*}{ Bağımsız Değişken } & \multicolumn{2}{|c|}{ Bağımlı Değişken: Kaygı } \\
\hline & Beta & $\mathrm{t}$ \\
\hline Algılanan İş Güvencesi & -.273 & 7.193 \\
\hline $\mathrm{R}^{2}$ & \multicolumn{2}{|c|}{.273} \\
\hline $\mathrm{F}$ & \multicolumn{2}{|c|}{$10.950^{* *}$} \\
\hline
\end{tabular}

$$
\mathrm{p}<0,01
$$

Tablo 3 incelendiğinde, kurulan regresyonun $\% 1$ anlamlılık düzeyinde istatistiksel olarak anlamlı olduğu elde edilmiştir $(p<0,01) . \quad R^{2}$ değerine bakıldığında, çalışanların kaygı düzeyindeki değişiminin yaklaşık \%27'sinin algılanan iş güvencesi tarafından açıklandı $\breve{g}_{1}$ bulunmuştur. Ayrıca, çalışanların kaygı düzeylerini açıklamada algılanan iş güvencesinin istatistiksel olarak anlamlı bir etkiye sahip olduğu tespit edilmiştir. Buna göre, algılanan iş güvencesi algısı azaldığında çalışanların kaygı düzeylerinin arttığı sonucu elde edilmiştir.

\section{TARTIŞMA VE SONUÇ}

İş güvencesizliği, birey, örgüt ve toplum üzerinde olumsuz etkilerde bulunmaktadır. $\mathrm{Bu}$ olumsuz etkilerin ortaya konulması, bu konuda yapılması gerekli olan düzenlemelere yol gösterici olacaktır.

Çalışmada, cinsiyet değişkenine göre, çalışanların iş güvencesi algısı açısından anlamlı bir farklılık tespit edilememiştir ( $p>0.05)$. Literatürde bu alanda yapilan çalışmalara baktığımızda farklı bulgular dikkati çekmektedir. Örneğin, Önder ve Wasti (2002) tarafından yapılan çalışmada, erkek ve kadın çalışanlar arasında iş güvencesi algısı açısından anlamlı bir farklılık tespit edilememiştir. Bu çalışmadan elde edilen sonuçların, Önder ve Wasti (2002) tarafından yapılan çalışmadan elde edilen bulgularla paralellik gösterdiği söylenebilir. Poyraz ve Kama (2008) tarafından yapılan çalışmada ise, erkeklerin iş güvencesi algısı kadınlardan yüksek bulunmuştur. Çalışmalar arasında böyle bir farklılık olması farklı örneklemler üzerinde farklı ölçüm araçları kullanılmasından kaynaklanıyor olabilir.

Katılımcıların medeni durumlarına göre yapılan analizlerde de anlamlı bir farklılık tespit edilememiştir. Poyraz ve Kama (2008) tarafından yapılan bir çalışmada ise evli olan katılımcıların iş güvencesi algısı bekâr olan katılımcilara göre daha yüksek bulunmuştur.

Yaş gruplarına göre iş güvencesi algısı ile ilgili test sonuçlarına baktığımızda en yüksek iş güvencesi algısına sahip grubun 31-45 yaş arası grup olduğu tespit edilmiştir. Önder ve Wasti (2002) çalışmasında ise, en yüksek iş güvencesi memnuniyeti sahip grup 46 ve üstü yaş grubu bulunmuştur. Poyraz ve Kama (2008) tarafından yapılan çalışmada ise yaş arttıkça iş güvencesi algısının arttığ

Çalışanların eğitim durumlarına göre yapılan analizlerde ise, eğitim durumu arttıkça iş güvencesi algısının arttığ $\breve{1}_{1}$ tespit edilmekle beraber aradaki farklılık istatistiksel olarak anlamlı bulunmamıştır. Diğer taraftan, Önder ve Wasti (2002) tarafından yapılan çalışmada da eğitim ile iş güvencesi algısı arasında anlamlı bir ilişki bulunamamıştır. 
Çalışanların işteki konumlarına göre iş güvencesi algıları ile ilgili karşılaştırmaya baktığımızda beklenildiği üzere sözleşmeli çalışanların iş güvencesi algısı, sürekli çalışanlara göre anlamlı bir şekilde daha düşük bulunmuştur. Clarke (2005) çalışmasında da benzer bulgular tespit edilmiştir.

Diğer taraftan yapılan regresyon analizi sonucunda ise, iş güvencesi algısını çalışanların kaygı düzeyleri üzerinde anlamlı bir etkide bulunduğu gözlemlenmiştir. $\mathrm{Bu}$ konuda yapılan çalışmalara baktığımızda da benzer bulgular dikkati çekmektedir. Boya ve diğerleri (2008) tarafından özel sektör hastanelerinde çalışan 462 kişi üzerinde yapılan bir çalışmada iş güvencesi algısının çalışanların kaygı ve depresyon düzeyleri üzerinde anlamlı bir etkide bulunduğu görülmüştür. Aynı şekilde Boya ve diğerleri (2009) tarafından bir gemicilik firmasında çalışan 125 kişi üzerinde yapılan çalışmada iş güvencesizliği ile fiziksel ve zihinsel sağlık şikâyetleri arasında anlamlı bir ilişki tespit edilmiştir.

\section{Kaynaklar}

Bakan, İ. ve Büyükbeşe, T. (2004), "Çalışanlarn iş güvencesi ve genel iş dauranışlar ilişkisi: Bir alan çalı̧̧ması", Erciyes Üniversitesi İktisadi ve İdari Bilimler Fakültesi Dergisi, 23, 3559.

Boya, F. Ö., Demiral, Y., Ergör, A., Akdavar, Y. and Witte, H.D (2008), "Effects of perceived job insecurity on perceived anxiety and depression in nurses", Industrial Health, 46, 613-619.

Burgard, S. A., Brand, J. E. and House, J. S. (2008), "Perceived job insecurity and worker health in the United States", http://www.psc.isr.umich.edu/pubs/pdf/rr0 8-650.pdf (Erişim Tarihi: 15.01.2012).

Clark, L.Y (2005), "Moderators of the effects of perceived job security: A comparison of temporary and permanent employees", Queensland University of Technology, Queensland, Austraila.

Çakır, Ö. (2007), "İşini Kaybetme Kaygısı: İş Güvencesizliği", Çalışma ve Toplum, 1, 117140.
Dığın, Ö. ve Ünsar, S. (2009), "Çalışanların iş güvencesi algısinun belirleyicileri ve iş güvencesinden memnuniyetin organizasyonel bağglllk, iş stresi ve işten ayrılma eğilimine etkisi üzerine yapılan bir araştırma", 17. Ulusal Yönetim ve Organizasyon Kongresi Bildiriler Kitabı, 106-112.

Erlinghagen, M. (2008), "Self-perceived job insecurity and social context: A multi-level analysis of 17 european countries", European Sociological Review, 24(2), 183-197.

Hartley, J., Jacobson, D., Klandermab, N. and van Vuuren, T. (1991), "Job Insecurity: Coping with Jobs at Risk", Sage Publications, London.

Önder, Ç. ve Wasti, S. A. (2002), "İ̧̧ güvencesi endeksi ve is güvencesi memnuniyeti ölçeği: güvenirlik ve geçerlik analizi", Yönetim Araştırmaları Dergisi, 2(1), 23-47.

Öner, N. ve Le Compte, A. (1983), "DurumlukSürekli Kaygı Envanteri El Kitabı", Boğaziçi Üniversitesi Matbaası, 1. Baskı, İstanbul

Poyraz, K. ve Kama, B. (2008), "Algulanan iş güvencesinin, iş tatmini, örgütsel bağlllık ve işten ayrlma niyeti üzerindeki etkilerinin incelenmesi", Süleyman Demirel Üniversitesi İ.I..B.F Dergisi, 13(2), 143-164.

Seçer, B. (2009), "İ̧̧ güvensizliği: Türleri, Başa Çıkma Süreci, Belirleyicileri ve Sonuçları", "Çalışma Yaşamında Davranış" (editörler: Aşkın Keser, Gözde Yılmaz, Şenay Yürür), Umuttepe Yayınları, Kocaeli,307-344.

Sverke, M., Hellgren, J. and Naswall, K. (2002), “No security: A meta-analysis and review of job insecurity and its consequences", Jourmal of Occupational Health Psychology, 7, 242-64.

Witte, H. D. (2005), "Job insecurity: Review of the international literature on definitions, prevalence, antecedents and consequences", SA Journal of Industrial Psychology, 31 (4), 16. 